\section{ENERGY AND CLIMATE}

\section{Research and \\ Education Essential}

The last COST Interaction Conference (Basel, 9-11 October 1995) focussed on reasonable exploitation of the Earth's resources, the development of new processes, products and services, and the human dimension in science and society. E.W.A. Lingeman, the Secretary of the EPS Action Committee for Physics and Society, reports that speakers dealing with energy-related aspects stressed the need for research and technical development, detailed analysis and public awareness.

\section{Renewables: Fully Competitive}

An analysis of the evolution of energy systems, and of their related discoveries and inventions over the last century, shows a complex picture of progress in terms of cost, quality, variety, and use of energy. New needs have developed owing to the convergence of technology and social developments (e.g., the motor car and individual mobility). They were enabled by a wider diversity of energy sources and decreasing costs. Several renewable energy technologies are today following exploitation paths similar to that of oil. Based on this observation, G. Dupont-Roc (Shell, London) described two scenarios for non-renewable energy (sustained growth and dematerialization) which have been developed by exploring different ways of meeting energy needs.

In sustained growth, productivity improvement in supply leads to energy being abundant at competitive prices and gives limited incentive for energy conservation. In dematerialization, needs are met through technologies and systems requiring a much reduced energy input since productivity-in-use is much larger. For both these market-driven scenarios, $\mathrm{CO}_{2}$ emissions from fossil fuels peak before the middle of the next century and then decline, possibly leading to a stabilization of atmospheric $\mathrm{CO}_{2}$ content of about twice the pre-industrial level.

\section{EPS 1996 Energy-Related Events}

Organized by the Action Commizttee for Physics and Society (ACPS) and the Interdivisional Group for Physics for Development (IGPD)

May $10-13$, CERN, Geneva, Switzerland

Economy - Energy - Entropy: Europhysics Study Conference (EurophysNet at http://epswww.epfl.ch/conf/energy96.html)

Contact: R. Dekyser (Chair, ACPS)

Institute for Theoetical Physics, Physics Dept., KU Leuven, Celestijnenlaan 200D, B-3001 Leuven Tel.: + 32 (16) 327235 , Fax: + 32 (16) 327986 E-mail: raf.dekeyser@fys.kuleuven.ac.be

September 16 - 20, Seville, Spain

Solar Cells - A New Challenge for the Mediterranean Area: Joint ACPS/IGPD Workshop (Satellite to EPS-10 Gen. Conf.) (EurophysNet at http://epswww.epfl.ch/conf/solarg6.html) Contact: A. Suzor-Weiner (Chair, IGPD)

Laboratoire. de Photophysique Móleculaire, Bât. 213, Université Paris-Sud, F-91405 Orsay Tel: +33 (1) 69417468 , Fax: +33 (1) 69416777 E-mail: annick@scipion.ppm.u-psud.fr

\section{Market: Analysis Important}

In the case of transport, responsible for a large proportion of energy consumption, the slow but steady emergence of a European economy is provoking a wide spectrum of far-reaching changes in transport systems. However, recent shifts in legal regulation that emphasise private initiatives are tending to neglect negative effects on the environment. Consequently, there is a need to design new transport systems which ensure sustainable development at the local, regional and international scales. An analysis by P. Nijkamp (Free University, Amsterdam) of the environmental consequences of transport systems which can be envisaged for the next century concluded that new private, as opposed to public, modes of transport are the most competitive.

In the case of power supply, the three major functions of a power system (generation, transport, distribution) essentially determine its scale, scope and density. Recent work aims to assess the performance of competing structures for the electricity supply industry. A. Verbruggen (University of Antwerp) described an analysis based on five criteria (sustainability, economic efficiency, regulatory efficiency, equity, and institutional feasibility). Among the structures considered there is the socalled normative model which builds upon experience in several countries (notably The Netherlands and the UK) where the consumer cannot choose and negotiate. Instead, the system is split up into supply, the bulk market and the retail market, with this unbundling of functions being the basis for transparency and competition. Other models include vertical integration and open competition, the latter suffering from the disadvantage that it does not differentiate between independent generators who do and do not sell their own power.

\section{Sources: Science Contributes}

The quality of life largely depends on the availability of energy sources. The present worldwide energy consumption has reached about $8000 \mathrm{GW}$ and is expected to increase sharply owing to rising demand in developing countries. This implies an enhanced depletion of fossil reserves and further aggravation of environmental pollution. Our quality of life is threatened unless renewable energy resources can be developed in the near future. M. Grätzel (EPFL, Lausanne) pointed out in his talk on renewable energy sources that chemistry is expected to make important contributions to identifying environmentally friendly solutions to the energy problem. An especially attractive option lies in the development of systems that mimic natural photosynthesis in the conversion of solar energy. They harvest sunlight to produce electricity or to drive an uphill chemical reaction. A molecular photovoltaic device, with an overall efficiency for converting solar energy to electricity of about $10 \%$ and still improving, has been developed. It is based on incorporating charge-transfer sensitizers in nanocrystalline oxide films. The low cost of this new type of solar cell should benefit large-scale photovoltaic applications. The device has also led to a new approach for energy storage based on intercalation. Such systems will undoubtedly promote the acceptance of renewable energy technologies, not the least by setting new standards for convenience and cost.

\section{Climate: Research Needed}

Over the last 20 years, paleoclimatic reconstructions have emphasized the role of insulation changes in driving the the Earth's climate. The study of ice cores and marine sediments show that long-term climatic changes correspond to orbital 
periodicities $\left(19,23,41,100 \times 10^{3}\right.$ years), as proposed by Milankovitch. But the theory says nothing about variations on shorter time scales. J.-C. Duplessy (CNRS, Gif-sur-Yvette) reported that recent work has revealed much more abrupt climatic changes. These develop within a few decades and are superimposed on the Milankovitch-type variations. The main physical factor responsible for the rapid variations seems to be the hydrological cycle driving the surface salinity/density of the North Atlantic Ocean. Rapid climatic changes arose during ice ages because massive iceberg discharges occurred in response to disequilibrium of the ice-sheet. They resulted in major injections of freshwater into the ocean. However, climatic variations of great amplitude also seem to have occurred during the ice ages, suggesting that iceberg discharge is not the only factor perturbing ocean circulation and the salinity of the surface of the North Atlantic. The mechanisms involved in such changes must be understood in order to evaluate the magnitude of climatic change resulting from the enhanced greenhouse forcing arising from man's activities.

\section{Energy Use: Learning Process}

B. Dessus (CNRS, France) argued that many people believe that today's approaches to energy development are leading down blind alleys. If current trends continue, a critical point will be reached 50 to 100 years from now, with the simultaneous depletion of resources (especially oil) and a rise in the level of pollution (greenhouse gases and high-level radioactive waste). The idea is spreading that a choice must be made between development and protection of the environment.

The very basis of this reasoning which must be changed. Work carried out over the past few years has shown that exploiting science and technology to master energy efficiency is not only indispensable to avoid the deadlock mentioned above but is also a major component of development. It has also been shown that economic aspects are no longer an obstacle since the investment required to improve energy efficiency, and to use renewable energy at the level necessary for the hoped for development, is not larger than the investment required to produce additional energy based on current trends. The main obstacles are fundamentally institutional and human. A changeover from one method of energy management to another requires the organization of an immense transition. It implies the undertaking of a collective learning process affecting government policy, energy production, land-use, and financial systems. One has to build up an action programme which brings international resources to this huge learning process.

\section{Cost}

European Cooperation in the field of Scientific and Technical Research is a framework for coordinating national research on a European level. COST was set up in 1971 and national organizations, institutes, universities, and industries in non-COST countries, and especially from central and eastern European, have participated since 1981 if there is a justified mutual interest. Flexible, à la carte "COST actions" consist of basic and pre-competitive research as well as activities of public utility. European Union (EU) institutions play an important role, but in contrast to EU programmes, COST collaboration does not require an agreed overall research policy. It focuses instead on specific themes for which there is particular interest. There are 115 COST actions, each managed by a committee. Only the "Application of Ion Beam Analysis" action involves physics directly.

\section{Knowledge, and Nothing but Knowledge}

\author{
Huub Eggen of the Foundation for Fundamental Research \\ (FOM) reports on several recent assessments of science \\ policy in The Netherlands.
}

Knowledge is the key word in Dutch science and technology policy at the moment. In 1994, the Dutch organization for applied science research (TNO) issued its third Strategic Plan, called "Putting Knowledge to Work". In May 1995, the Netherlands Organisation for Scientific Research (NWO) issued its policy document for the period 1996-2001, entitled "Knowledge Enriches", and one month later the ministries of economic affairs; education, science and culture; and agriculture, environment and fisheries published a joint policy paper called "Knowledge in Action". All these documents state that knowledge and a healthy knowledge infrastructure are of the utmost importance for the Dutch economy and for Dutch society in general. After all, apart from natural gas and a fertile soil there are no natural resources in The Netherlands other than brains. According to this view, The Netherlands have to concentrate on innovation in knowledge and technology. On the basis of several recent studies, the level of Dutch scientific research and the international visibility of its research are satisfactory.

People in industry and government are worried, however, about Dutch industry's relatively meagre level of advanced technology and ability to innovate. That is what everybody is focussing on. The TNO states that knowledge has to be translated into advanced products for the market; this will lead to, amongst other things, more jobs. TNO sees as a major role for itself the transfer of knowledge to medium- and small-scale companies. NWO stresses that science's greatest influence on generating new innovative power comes from interdisciplinary and multidisciplinary research. So the organization wants to actively pursue this kind of research. A high quality of research remains, however, the key criterion for funding by NWO. The government document focuses on the need to stimulate industrial activities with a high knowledge content. The ministers propose to establish a small number of top research institutes as centres of excellence to bring providers and users of knowledge closer together and to stimulate the use of essential enabling technologies.

\section{Sources of information}

- TNO has available an English version of its strategy document, called "Strategy Document, Abridged Version". It can be ordered from the TNO Corporate Communications Department, which can be reached through TNO's WWW server at http://www.tno.nl/home/index.html

- The NWO policy document is available in English (entitled "Knowledge enriches"). More information on NWO is available from news@nwo.nl or via WWW at http://www.nwo.nl/

- The government policy document is available in English (it is called "Knowledge in Action") and can be reached through the WWW server of the Ministry of Economic Affairs at http://www.minez.nl/ under the heading "Technologie". 